\title{
MORFOSCOPIA DA FRAÇÃO AREIA DE FORMAÇÕES ALÚVIO- COLUVIAIS: O QUE REVELA A ASSINATURA DE GRÃOS DE QUARTZO
}

\author{
Renata Jordan Henriques $^{(\mathrm{a})}$, Roberto Célio Valadão ${ }^{(\mathrm{b})}$ \\ (a) Mestranda pelo Programa de Pós-graduação em Geografia da Universidade Federal de Minas Gerais, E-mail: \\ renatajhques@gmail.com \\ (b) Professor Titular no Departamento de Geografia da Universidade Federal de Minas Gerais, E-mail: \\ valadao@ufmg.br
}

Eixo 10: Sistemas geomorfológicos: estrutura, dinâmica e processos.

\begin{abstract}
Resumo
A superfície é modelada por materiais incoesos de gênese alóctone ou autóctone. No contexto do território brasileiro, dada suas condições ambientais, essas formações superficiais possuem considerável espessura podendo haver linhas de fragmentos grossos em seu meio, isto é, stonelines. Para o trabalho foi escolhido um recorte de talude às margens da rodovia MG-010 ao norte de Belo Horizonte em Minas Gerais em virtude de uma expressiva stoneline integrada por seixos de quartzos de origem aluvial (alóctone) inseridos em uma formação aparentemente eluvial (autóctone). O objetivo é aplicar o método de morfoscopia de areia na fração fina em uma seção vertical e verificar se é revelado o caráter alóctone das formações. Os resultados mostram-se satisfatórios e revela uma marcada descontinuidade entre forma e textura dos grãos situados acima e abaixo da stoneline. Isto permite avaliar que são materiais de origem alóctone (alúvio-coluviais) ainda que seu aspecto seja de materiais autóctones.
\end{abstract}

Palavras chave: Formações superficiais; Stoneline; Mofoscopia de areia

\section{Introdução}

Sobre a superfície distribuem-se materiais incoesos de espessura variável que contribuem à esculturação do modelado do relevo, o qual Queiroz Neto (2001) utiliza o termo geral "formações superficiais" para designá-los. Esses materiais são originados a partir da interface entre o arcabouço geológico e sua interação entre agentes exógenos, tais como temperatura, disponibilidade hídrica e atividade biológica (THOMAS, 1994). Na história de formação desses materiais, estes podem ter sido mobilizados (alóctones), por exemplo, por transporte gravitacional de massa (colúvio) ou escoamento hídrico fluvial (alúvio), ou ainda serem continuamente alterados in situ (elúvio), ou seja, materiais alterados a partir de sua matriz litoestrutural original (CASSETI, 2005).

Pelas observações de Aubert e Segalen (1966) no continente africano e por Ab'saber (1962) em território brasileiro, também é recorrente encontrar aglomerações de fragmentos de materiais grossos inseridos nas coberturas que recobrem a superfície. Por definição linhas de pedra (HIRUMA, 2007; SANTOS et al. 2010), stonelines (BIGARELLA, 1994; SEGALEN, 1969), linhas de seixos 
(HIRUMA, 2007), pavimentos detríticos (PENTEADO, 1983) ou horizontes inhumados de cascalho (AB’SABER, 1962) são sinônimos para essas concentrações de fragmentos grossos. Sua composição pode variar, bem como sua espessura na cobertura superficial (SEGALEN, 1969).

Investigar sua gênese requer cautela, pois, estas podem ser o resultado de múltiplos estágios evolutivos que culminaram à sua atual configuração cuja forte contribuição geoquímica atuante em condições climáticas tropicais pode mascarar sua procedência autóctone ou alóctone. Conforme Schaefer (2001), nessas condições climáticas há o favorecimento de transformações geoquímicas e bióticas que contribuem à homogeneização in situ das formações superficiais. Isto torna complexa a interpretação sobre a gênese de stonelines em razão da maioria dos registros entre sua gênese e a atual situação terem sido apagados.

Ao norte da capital Belo Horizonte encontra-se o contexto ambiental do carste de Lagoa Santa, isto é, um sistema modelado, sobretudo, por meio da ação hídrica que, por sua vez, promove a dissolução geoquímica de rochas carbonáticas (SILVA, 1995). A cobertura superficial que ocorre nesse ambiente revela recorrentemente características típicas da classe de Latossolo (EMBRAPA, 2013) e por vezes pode apresentar stonelines de fragmentos de quartzo marcando o contato em seções verticais de formações que variam de cor vermelho no topo para amarelo na base (HOFMANN, 2014).

Essa diferença de cor por vezes é explicada conforme a circulação hídrica que percola as formações, sendo uma drenagem mais livre onde os materiais possuem cor mais vermelha em virtude do maior favorecimento de formação de hematita, ao passo que o trecho amarelo a circulação seria mais deficitária favorecendo a formação de goethita (PILÓ, 1998; HOFMANN, 2014). Stonelines, por sua vez, ocorrem, porém, não em todos os perfis observáveis em campo e investigados na literatura. Sua presença possui variadas interpretações quanto a sua gênese, sendo em campo também observado que possuem diferentes organizações, formas e resistência dos fragmentos. Isto é, encontra-se tanto stonelines de quartzos de arestas angulares e quebradiços quanto arredondados e resistentes. Para este trabalho foi escolhido o recorte de talude às margens da rodovia MG-010 na altura do município de Vespasiano (Figura 1). Nesse talude manifesta-se uma extensa stoneline de seixos de quartzos de gênese aluvial com arestas bem arredondadas, bem selecionados e resistentes. 


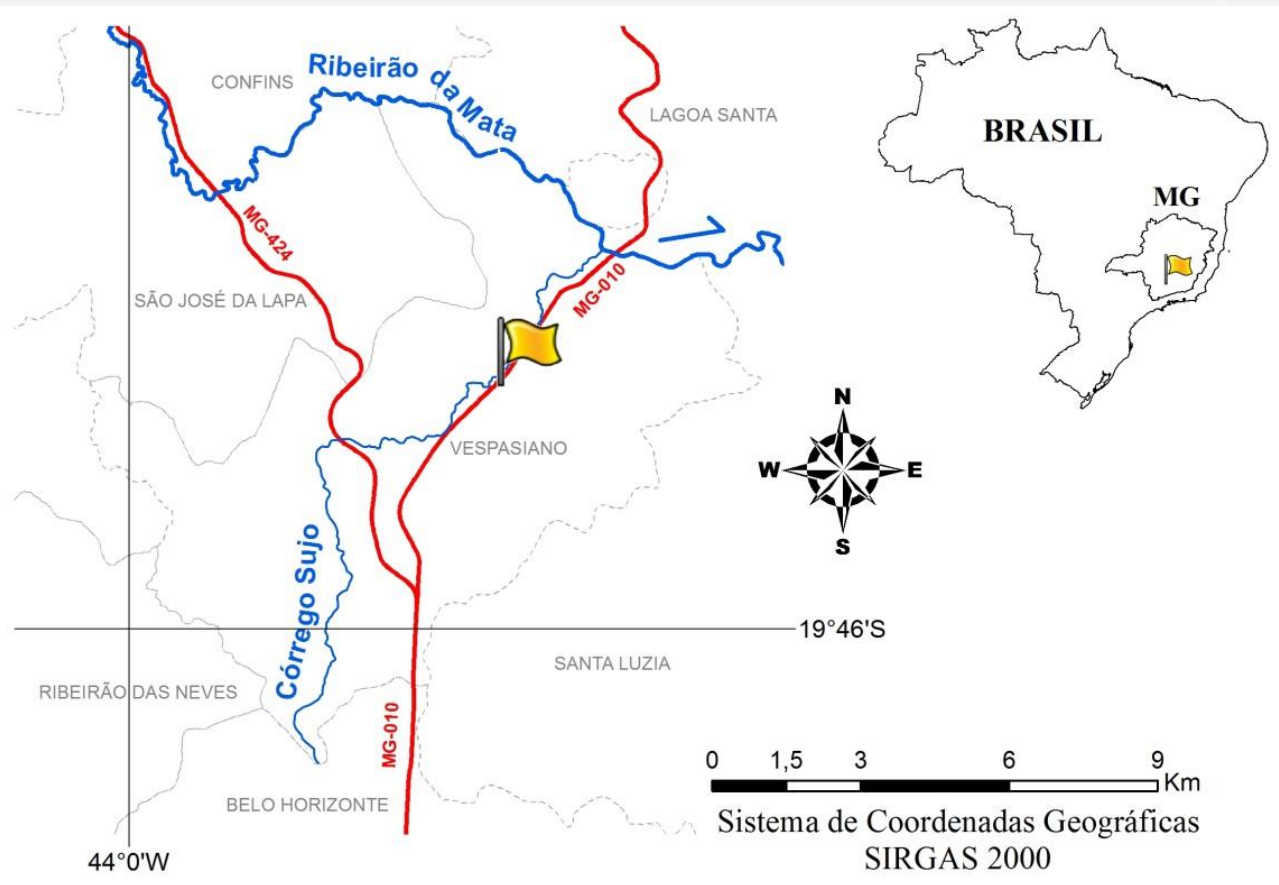

Figura 1: Localização da área investigada

Nesse contexto este trabalho objetiva aplicar o método de morfoscopia de grãos de quartzo na fração granulométrica areia fina $(0,05-0,21 \mathrm{~mm})$ como maneira de avaliar se é revelado o caráter alóctone dos cascalhos aluviais que formam a stoneline do talude investigado, bem como o comportamento dos grãos acima e abaixo desta. O método consiste em verificar o grau de arredondamento, circularidade, alongamento e textura dos grãos.

\section{Materiais e métodos}

Para investigar o comportamento da fração areia o corte de talude teve seus materiais organizados conforme metodologia de classificação de solos da Embrapa (2013). Em campo foram separados os horizontes pedológicos e coletada duas amostras de horizonte $\mathrm{A}$, duas de $\mathrm{B}$, duas no horizonte $\mathrm{C}$ na porção de aloterita, ou seja, no trecho superior do manto de rocha alterada onde as estruturas originais da rocha não se encontram mais preservadas, bem como duas amostras na faixa de stoneline. Ao total foram levadas oito amostras ao Laboratório de Geomorfologia e Sedimentologia do Instituto de Geociências da Universidade Federal de Minas Gerais.

No Laboratório as amostras foram secas ao ar e realizadas as seguintes etapas: (i) destorroamento manual, (ii) peneiramento para obter frações inferiores a areia $(<2,0 \mathrm{~mm})$ de terra fina seca ao ar (TFSA); (iii) dispersão de partículas por meio do método da pipeta, isto é, são pesados $20,000 \mathrm{~g}$ de TFSA em frasco polietileno e adicionados $25 \mathrm{molL}^{-1}$ de solução de hidróxido de sódio $(\mathrm{NaOH})$, somada a $100 \mathrm{ml}$ de água deionizada, posteriormente levado ao agitador do tipo Wagner a $50 \mathrm{rpm}$ por 
XVII Simpósio Brasileiro

de Geografia Fisica Aplicada

I Congresso Nacional

de Geografia Física

\section{OS DESAFIOS DA GEOGRAFIA FÍSICA NA FRONTEIRA DO CONHECIMENTO \\ Instituto de Geociências - Unicamp \\ Campinas - SP \\ 28 de Junho à 02 de Julho de 2017}

16 horas ininterruptas para dispersar as partículas menores e permanecer em repouso. Após passar o tempo necessário, a mistura é colocada em uma peneira de malha $0,053 \mathrm{~mm}$ e lavada até que retenha apenas as frações areia. Posteriormente essa areia é levada para a estufa para (iv) retirada da água que restou durante a lavagem e (v) separada em peneira a fração fina $(0,05-0,21 \mathrm{~mm})$.

Com as amostras individualizadas de area fina, estas foram separadas em cem grãos por horizonte amostrado em campo totalizando 800 partículas e, com auxílio de lupa trinocular com luz refletida, aumento de 40x e registro fotográfico, foram classificados conforme arredondamento de Cox (1927), circularidade de Pentland (1927), índice de alongamento de Ribeiro e Bonetti (2013) e textura de Bigarella et al. (1955) (Figura 3C). No Programa ImageJ foram gerados os valores para Arredondamento (Circularity pelo ImageJ), Circularidade (Round pelo programa) e Índice de Alongamento (Aspect Ratio), ao passo que a textura foi determinada visualmente. Para organização e sistematização visual do padrão morfológico dos grãos, foi adaptado e utilizado o Diagrama de Powers (GRAHAN, 1988) (Figura 3B).

A

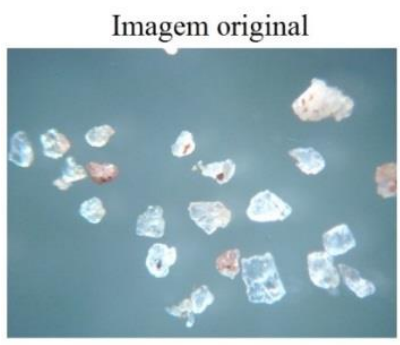

C

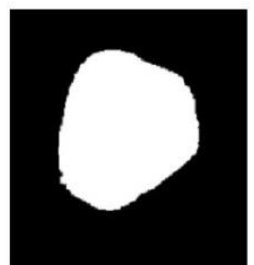

Arredondamento Cox (1927): 0,810 Circularidade Pentland (1927): 0,819 Índice de Alongamento Ribeiro e

Bonetti (2013): 1.130

Fonte: Adaptado de Ribeiro e Bonetti (2013).
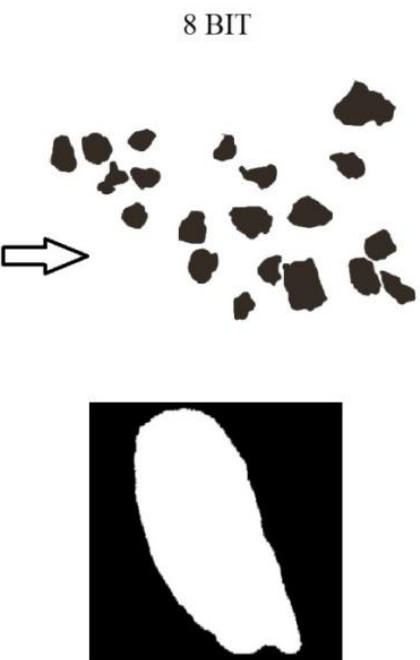

Arredondamento Cox (1927): 0,613

Circularidade Pentland (1927): 0,438 Indice de Alongamento Ribeiro e

Bonetti (2013): 1.964
B

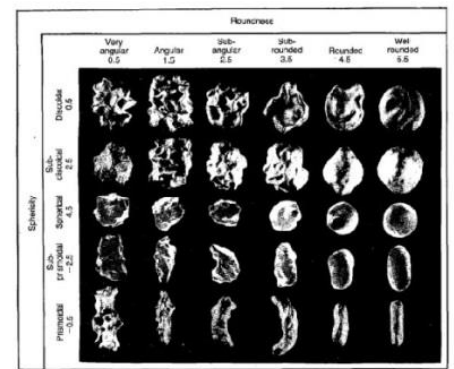

Fonte: Power (1982) citado por Grahan (1988)

Figura 3: Organização de procedimentos metodológicos

Para o uso do ImageJ é necessário o tratamento pretérito das fotografias. O tratamento de modo automático envolve converter as imagens para 8 BITS, nos quais os grãos ficam pretos e o fundo branco e o software faria sua leitura (Figura 3A). Todavia, em função de diferentes contrastes de tons e sombras na fotografia colorida original, a conversão direta para 8 BITS poderia gerar quantidades de ruído suficiente para tornar demorado, e até inviável, realizar sua posterior correção. Neste caso, para este trabalho, as fotografias foram tratadas manualmente no programa CorelDRAW X3 por meio do desenho e preenchimento de cada grão por polígono de vetores (Figura 3A). Com as fotografias 
adequadas à leitura, o ImageJ foi utilizado para geração dos valores de Índice de Alongamento, arredondamento e circularidade, sendo os dois últimos variando entre 0 e 1 , sendo 1 uma esfera circular perfeita. Os dados, por sua vez, foram tratados estatisticamente no programa Excel (2010) e confecionados boxplots para os valores gerados pelo ImageJ e gráfico de colunas para distribuição textural. Visualmente os dados de fotografias, estatística e distribuição de frequência de grãos foram organizados no programa CorelDRAW X3.

O conceito de arredondamento é associado ao grau de maturidade dos grãos o qual pode indicar, por exemplo, o tempo que dada partícula se encontra ativa no ciclo sedimentar, intensidade de transporte e distância de área fonte da matriz litológica (SUGUIO, 1973; DIAS, 2004). Suguio (1973) indica que quanto maior o arredondamento, logo, maior sua participação no ciclo, porém, há outros fatores que podem influenciar na forma dos grãos como a morfologia original dos minerais presentes nas rochas, sua clivagem, processos químicos in situ, dentre outros. Conforme Dias (2004) há diversos índices que visam calcular as medidas de arredondamento, sendo o principal o Índice de Rolamento de Wentworth (r1/R) que calcula o raio da curvatura pelo valor médio dos raios de curvatura de todas as arestas. Para este trabalho será utilizado o calculo propoto por Cox (1927) que atribui a área em função de seu perímetro $\left(4 \pi \mathrm{A} / \mathrm{p}^{2}\right)$.

Circularidade é um conceito às vezes apresentado como sinônimo de esfericidade, porém, para o cálculo de esfericidade seria necessário sua análise de forma tridimencional sendo a maioria dos índices calculados de maneira bidimensional (RIBEIRO e BONETTI, 2013). Circularidade corresponde na relação entre seu eixo principal e seu eixo menor, nas quais quanto mais próximos os valores, mais circular é a partícula (BLOTT e PYE, 2008). Conforme Blott e Pye (2008), Pentland (1927) desenvolveu uma fórmula que compara a área da partícula em função de seu eixo menor $\left(4^{\mathrm{a}} / \pi(\mathrm{L})^{2}\right)$ que, apesar do autor ter utilizado o termo "angularidade" também como sinônimo de "arredondamento", o cálculo é mais adequado a circularidade. O Índice de Alongamento, por sua vez, é um cálculo utilizado por Ribeiro e Bonetti (2013) que revela o quanto é alongada uma partícula.

Conforme Dias (2004), a textura também é um conceito que envolve variadas taxonomias, sendo a principal desenvolvida por Cailleaux e Tricart (1963). Estes organizaram os grãos em três principais categorias: (i) NU (Non-Usées) anguloso, (ii) EL (Émoussés-Luisants) boleado brilhante e (iii) RM (Rond-Mats) arredondado baço (DIAS, 2004). Para este trabalho foi utilizada a classificação de Bigarela et al. (1955) citado por Bertolini et al. (2016) na qual suas terminologias são lisa, mamelonar ou sacaroide que, por sua vez, ainda é classificada coforme seu brilho em polido ou fosco. As partículas lisas correspondem a grãos de superfície regular, sacaroides a grãos irregulares, ásperos, de arestas agudas, ao passo que o mamelonar é um meio termo entre liso e sacaroide. 


$\begin{aligned} & \text { XVII Simpósio Brasileiro } \\ & \text { de Geografia Fisica Aplicada }\end{aligned}$
$\begin{aligned} & \text { I Congresso Nacional } \\ & \text { de Geografia Física }\end{aligned}$

\section{Resultados}

A aplicação do método de morfoscopia de grãos de quartzo na fração areia mostra-se satisfatório à avaliação da procedência alóctone ou autóctone dos materiais. Os resultados das análises para o recorte de talude investigado corroboram para a acertiva dos materiais que integram a cobertura de formações superficiais tenham proveniência, sobretudo, alóctone. Em campo revela-se principalmente uma espessa formação de solum (horizontes A + B) com características de elúvio (autóctone), ao passo que no contato com o horizonte $\mathrm{C}$ (aloterita) há uma stoneline que apresenta atributos de materiais transportados (alóctones), sendo assim, uma descontinuidade intraperfil. Ao observar o comportamento de distribuição dos grãos de quartzos, estes também refletem tal descontinuidade o qual é possível notar pela significativa diferença entre os grãos mais arredondados situados acima e mais angulosos abaixo da stoneline (Figura 4). Dada organização permite avaliar que os materiais situados acima da stoneline são de procedência também alóctone (coluvial), porém, geoquimicamente esses materiais podem ter sido transformados e adquirido características de materiais autóctones.

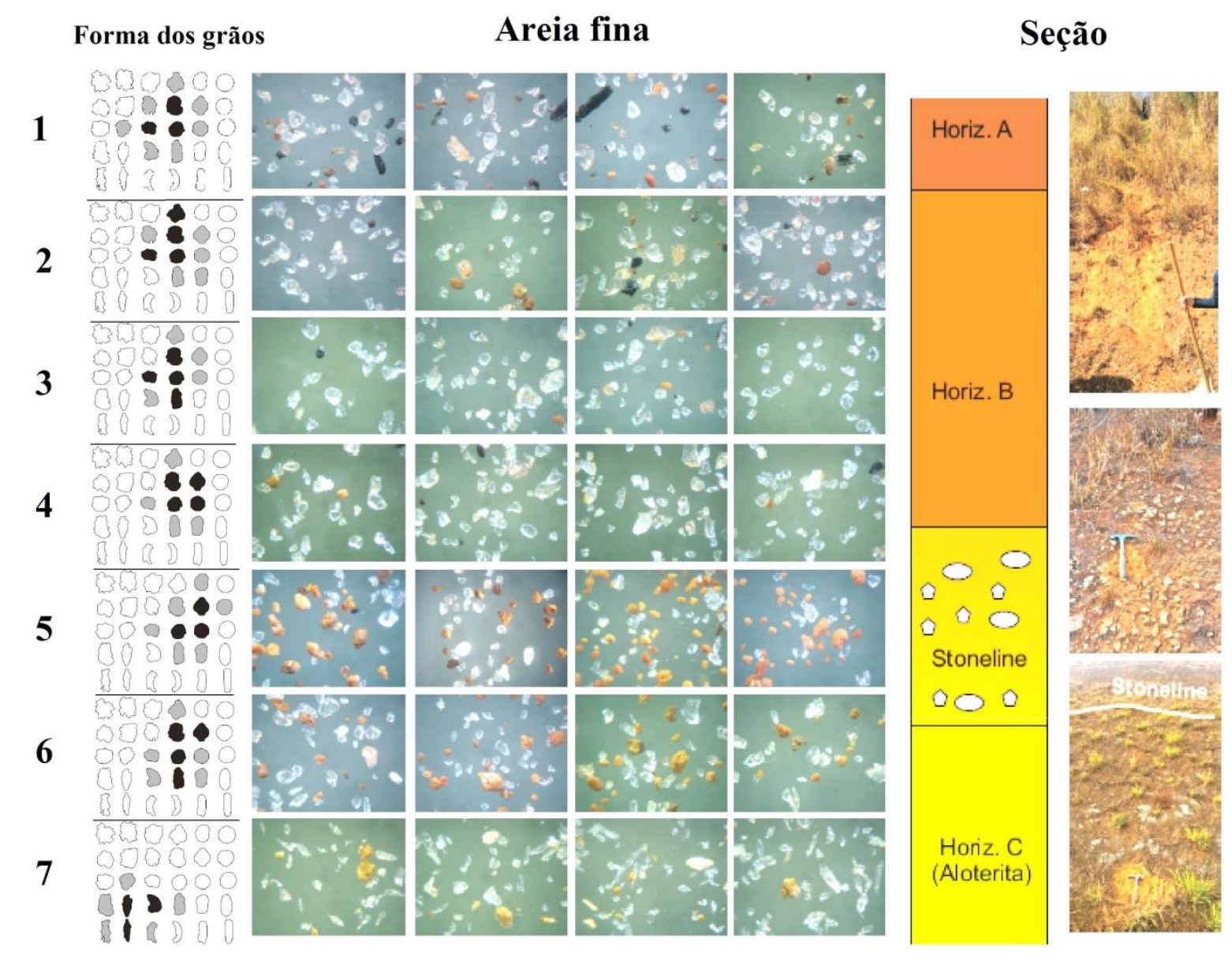

Figura 4: Seção esquemática do talude investigado e organização em perfil vertical sobre o comportamento de distribuição dos grãos de quartzo. 


\section{OS DESAFIOS DA GEOGRAFIA FÍSICA NA FRONTEIRA DO CONHECIMENTO \\ Instituto de Geociências - Unicamp \\ Campinas - SP \\ 28 de Junho à 02 de Julho de 2017}

Em âmbito estatístico os grãos de quartzo presentes acima da stoneline (seções 1 a 4) possuem mediana de arredondamento de 0,777 com variação entre 0,707 a 0,835 , enquanto a mediana de circularidade apresenta 0,675 de variação entre 0,541 e 0,798, ao passo que o índice de alongamento possui mediana 1.481 e valores que variam principalmente entre 1.253 e 1.881 sendo o extremo máximo de 3.227 na seção 3 (Figura 5).

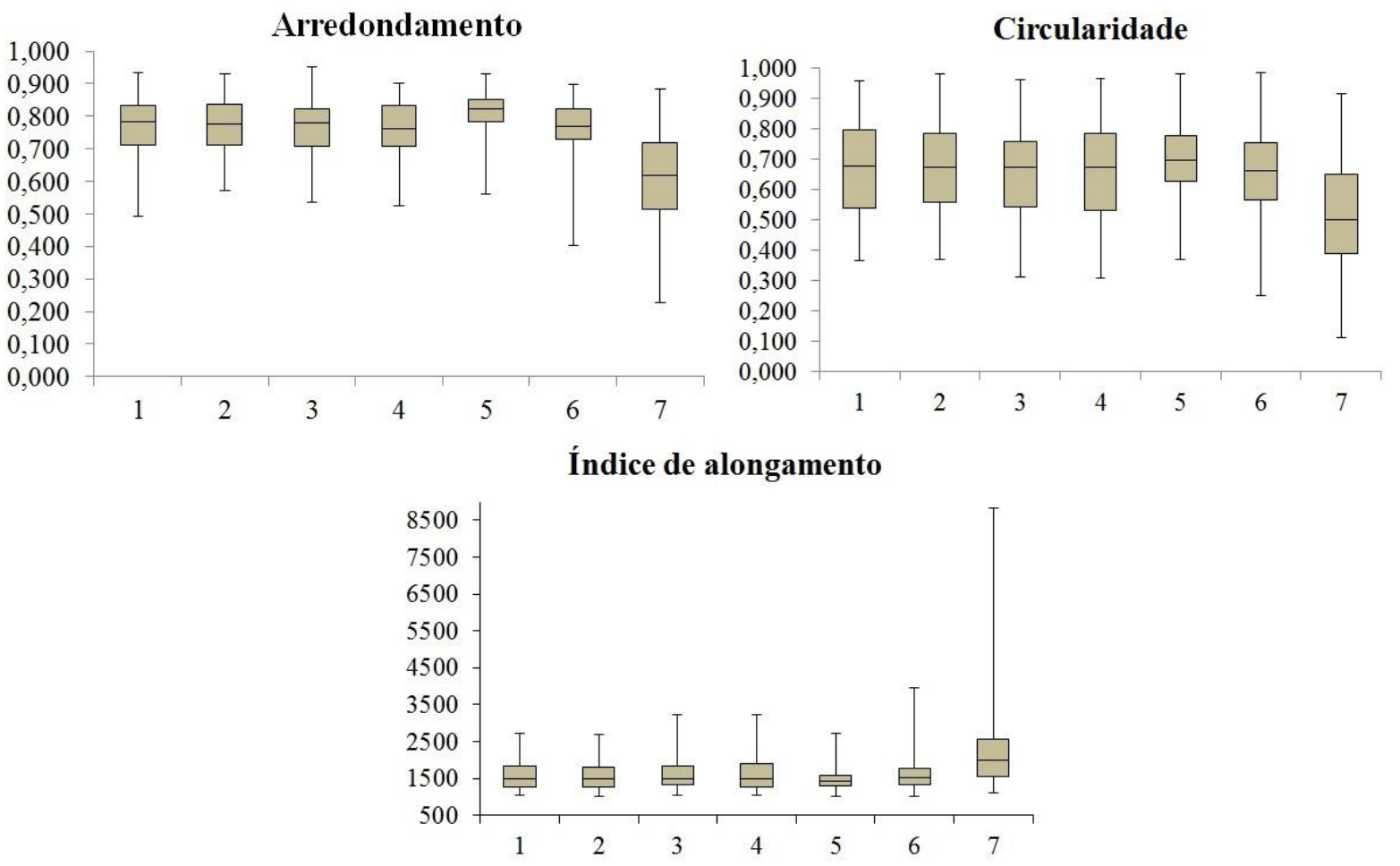

Figura 5: Análise estatística para a variação de Arredondamento, Circularidade e Índice de Alongamento.

Esses valores correspondem a grãos de morfologia predominante subarredondada com menores proporções de indivíduos arredondados e subangulares, bem como suas arestas são relativamente regulares e fragmentos, no geral, pouco alongados (Figura 6). A seção 2 exemplifica o comportamento típico dos grãos das seções 1 a 4, sendo a textura apresentando a superfície dos grãos predominantemente polida e variando a regularidade de suas arestas entre lisa a mamelonar. Nota-se que os fragmentos acima da stoneline tendem a apresentar maior recorrência de hematita, óxidos que envolvem os grãos de quartzo e fragmentos de matéria orgânica à medida que se aproxima da porção superior corresponde ao horizonte A pedológico (Figura 6). 


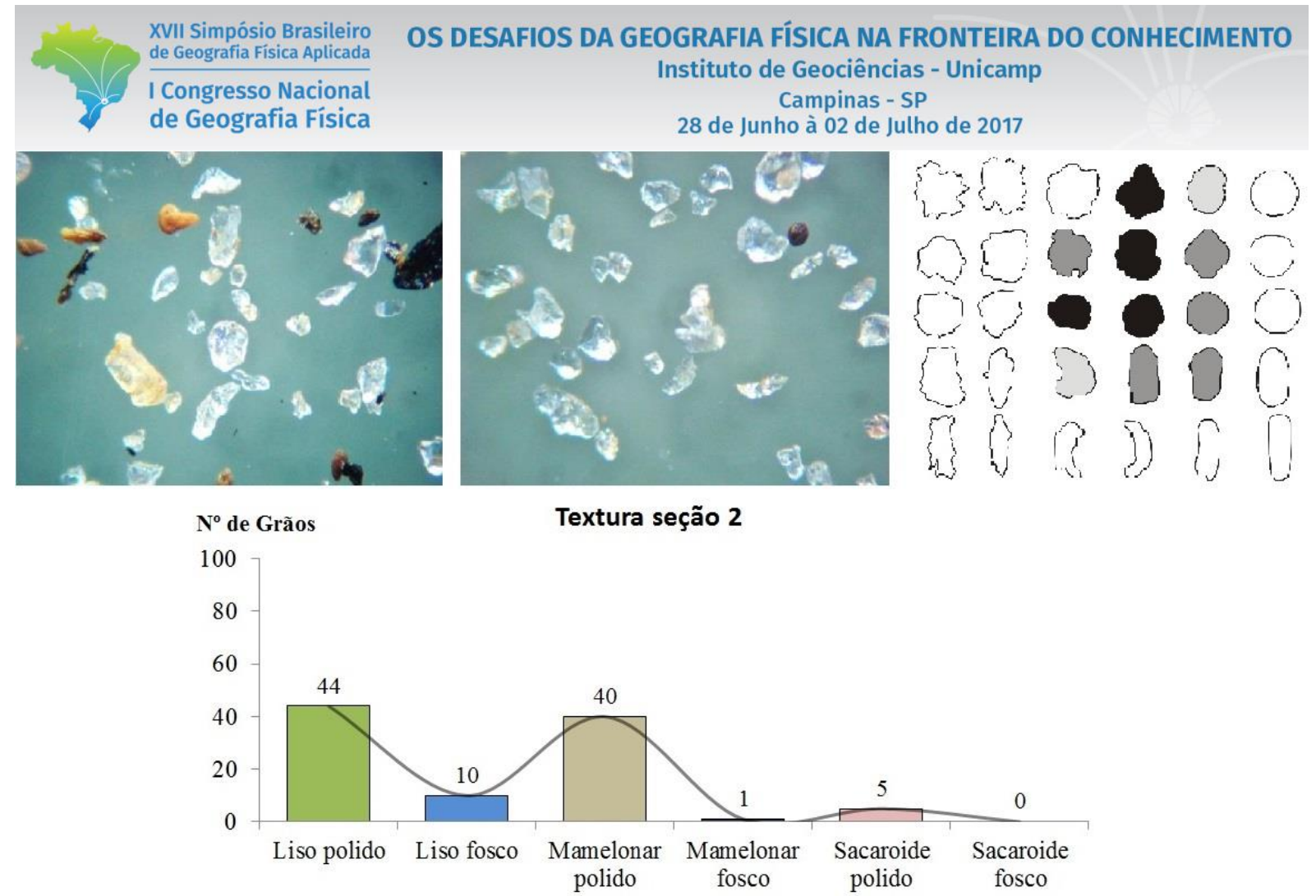

Figura 6: Seção esquemática 2 que representa o comportamento geral dos grãos entre as seções 1 e 4.

Os grãos situados na faixa de stonelines (5), por sua vez, apresentam uma considerável concentração de fragmentos bem arredondados sendo possível encontrar fragmentos circulares quase perfeitos, menores proporções de grãos subarredondados, bem como os menores índices para alongamento. Dada constatação é observada pelos valores gerados no ImageJ e pelo seu tratamento estatístico, sendo mediana de arredondamento de 0,822 com concentração que varia entre 0,781 e 0,852 , o que representa valores de maior arredondamento em relação ao grupo anterior (Figura 5). Bem como mediana de circularidade 0,697 e variação de 0,628 a 0,780, enquanto índice de alongamento mediano de 1.436 com variação entre 1.281 e 1.590 de limite máximo 2.706 , sendo tanto circularidade quanto índice de alongamento com valores mais concentrados (Figura 5).

A textura desses grãos é predominantemente liso fosco com quantidades significativas de liso polido e mamelonar polido (Figura 7). Notadamente muitos grãos de quartzos presentes na stoneline apresentam aspecto fosco e opaco assumindo uma cor em tom sépia (Figura 7). Alguns desses fragmentos também são encontrados de maneira mais pontual no solum e horizonte C, porém, tal qual ocorre na stoneline, esses grãos assumem textura de liso fosco no solum, todavia no horizonte C apresentam textura mamelonar fosco a sacaroide fosco. 


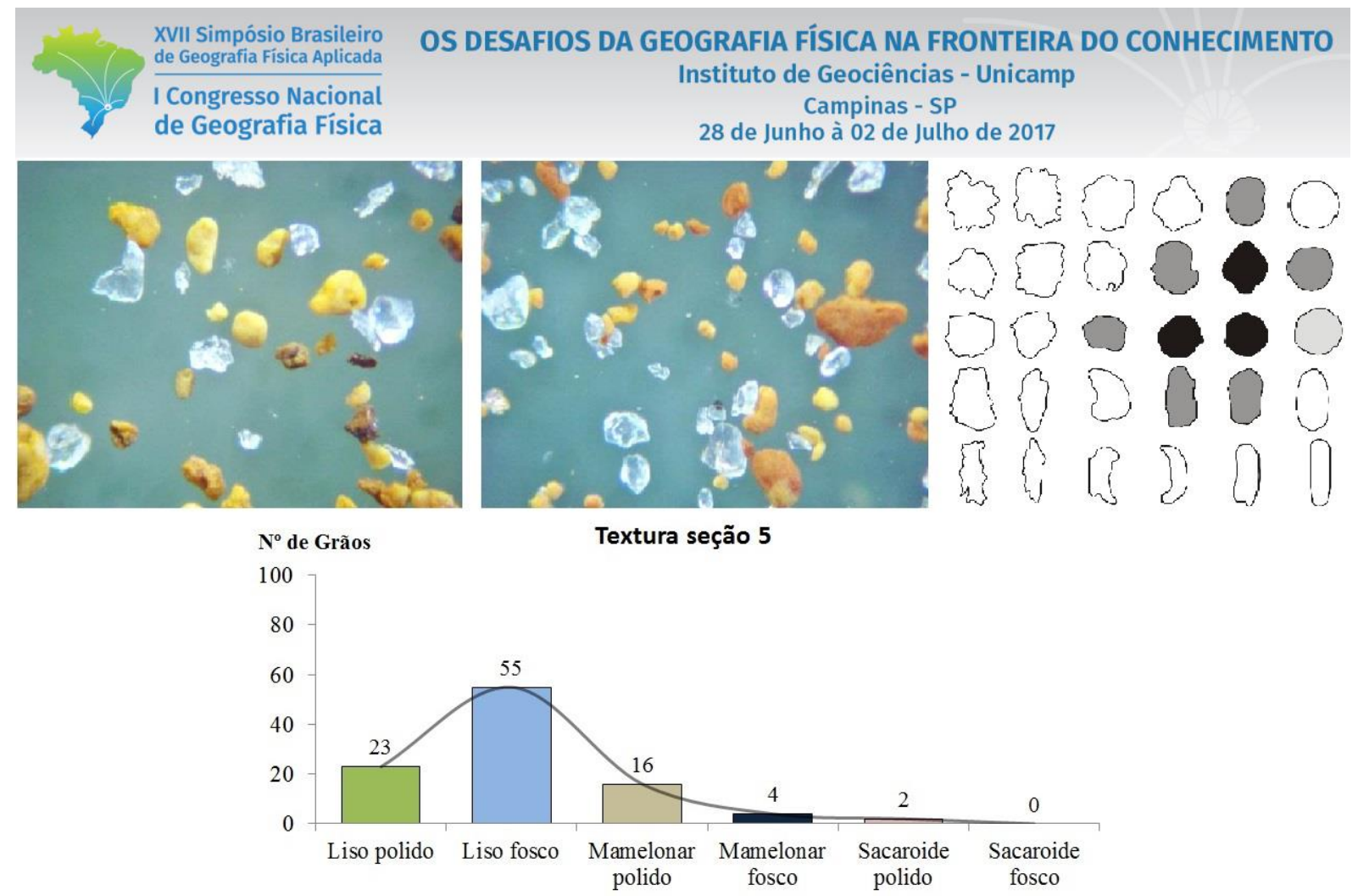

Figura 7: Seção esquemática 5 que exemplifica o comportamento geral dos grãos situados na faixa de stoneline.

Enquanto os grãos das seções 1 a 4 possuem um padrão semelhante ao que ocorre na stoneline, porém, quanto mais próxima desta, maior a concentração de grãos bem arredondados e circulares, à medida que se aprofunda nos domínio do horizonte $\mathrm{C}$ os grãos assumem particularidades bastante distintas. Conforme diagrama de boxplot (Figura 5), tem menor arredondamento em relação aos demais grupos, ou seja, mediana de 0,618, com variação geral entre 0,513 e 0,719. Revela também menor circularidade representada por mediana de 0,502 e variação de 0,389 a 0,650 . Bem como maior concentração de grãos alongados referentes a uma mediana de 1.991, variação entre 1.536 e 2.568 com fragmentos que chegam a 8.826 .

A textura também se mostra bastante distoante na qual há um predomínio de sacaroide polido e em seguida mamelonar polido (Figura 8). Os grãos de quartzos apresentam bem alongados, fraturados com raros grãos de superfície lisa. Para síntese dessas características a seção 7 representa a melhor amostra e corresponde ao ponto mais profundo coletado situado a aproximadamente $5 \mathrm{~m}$ abaixo da stoneline. 


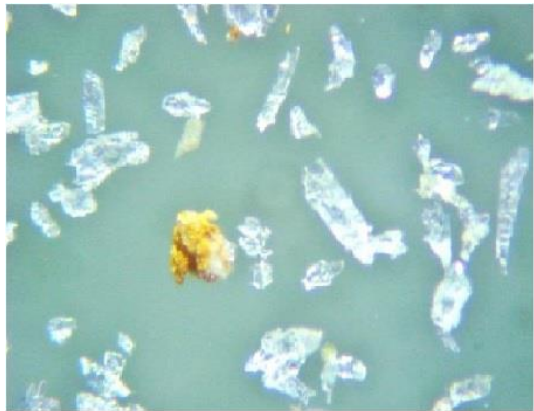

$N^{\circ}$ de Grãos

100

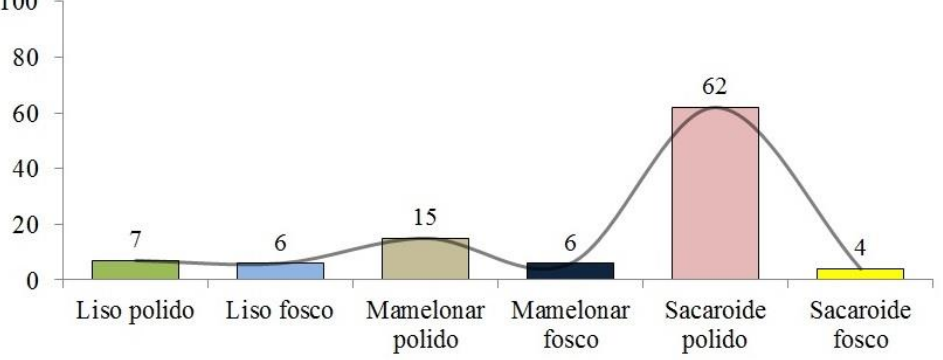

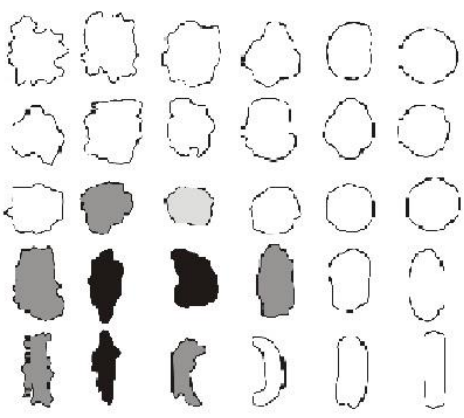

Textura seção 7

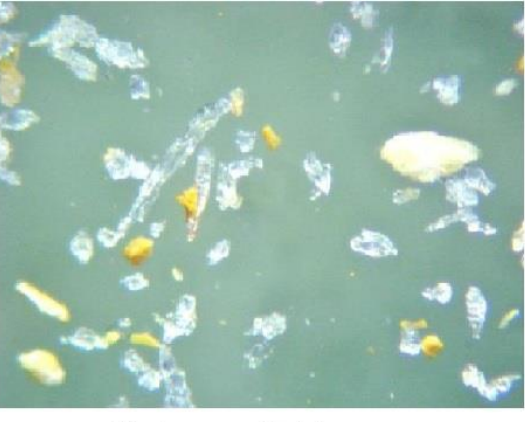

sco

Figura 8: Seção esquemática 7 referente ao comportamento geral dos grãos abaixo da stoneline no horizonte C.

Esses resultados corroboram de maneira microscópica para que a stoneline realmente possua gênese aluvial dada a notada concentração de grãos de quartzo de superfície lisa e arredondada, como também permite indicar que os materiais situados sobre essa stoneline possuem gênese, sobretudo, alóctone. Quer dizer esses materiais acima da stoneline podem corresponder a contribuições coluviais depositados sobre o remanescente do leito por onde passava um antigo curso d'água, cuja organização e características de seus seixos no perfil ainda resguardem esse momento de sua história.

É importante destacar a particularidade de haver atributos que ainda possam indicar um transporte fluvial, visto que há stonelines de quartzos encontradas na região da área investigada que não seja possível tal relação clara e direta de seus materiais a algum paleocanal. Isto em virtude da maioria dos registros possivelmente terem sido apagados por uma possível temporalidade mais profunda que esses materiais tenham sido submetidos a ação geoquímica atuante, como é o caso desses materiais encontrados no planalto de Lagoa Santa nas imediações do Aeroporto Internacional Tancredo Neves que atende Belo Horizonte (KOHLER, 1989).

\section{Considerações finais}

Diante dos dados é possível afirmar que a stoneline marca a principal descontinuidade na seção vertical do talude cujos grãos de quartzo situados acima possuem um comportamento distinto em relação àqueles situados abaixo. Comparando os grãos presentes na stoneline e nas formações superficiais situadas acima, revela-se que há maior similitude entre esses, sendo cada vez maior o 
arredondamento e regularidade da superfície dos grãos à medida que se aproxima da stoneline. Quanto maior a proximidade com o horizonte A, maior a recorrência de óxidos de hematita e matéria orgânica nas amostras. Os quartzos que integram a stoneline possuem a particularidade de possuir uma relativa elevada concentração de grãos de aspecto fosco, superfície lisa e cor sépia. Fragmentos como esses também são encontrados tanto acima quanto abaixo da stoneline, porém, de maneira pontual. Por fim, os grãos encontrados no horizonte C são os mais distoantes em relação aos demais, pois, a maioria dos quartzos está fraturada, angulosa, alongada e de superfície irregular.

\section{Agradecimentos}

Ao CNPq pela concessão da bolsa $\mathrm{n}^{\circ}$ 130655/2016-3 que permite a dedicação integral às investigações do mestrado e, por conseguinte, parte de resultados já desenvolvidos. Agradecimentos também aos colegas de pós-graduação Matheus Armond, Roberta Parreira e Davi Lopes pelo auxílio às coletas de amostras em campo, ao Laboratorio de Geomorfologia e Sedimentologia da Universidade Federal de Minas Gerais pela disponibilidade de aparelhos às realizações das análises e à professora Giovana Parizzi do Departamento de Geologia da UFMG pelo empréstimo de lupa trinocular.

\section{Referências bibliográficas}

AB'SABER, A. N. Um conceito de geomorfologia a serviço das pesquisas sobre o quaternário. Geomorfologia. São Paulo. Instituto de Geografia USP, v.19, p. 1-23,1962.

AUBERT, G.; SEGALEN, P. Project de classification des sols ferrallitiques. Cahier ORSTOM-Pédologie IV, 4, p.97-112, 1966.

BERTOLINI, W.Z.; da COSTA, I.M.; de LIMA, G.L. Morfoscopia e morfologia da cobertura pedológica às margens do rio Uruguai no oeste de Santa Catarina. Anuário do Instituto de Geociências - UFRJ. v.39, n.3, p.71$78,2016$.

BIGARELLA, J.J.; HARTKOPF, C.C.; SOBANSKI, A.; TREVISAN, N. Textura superficial dos grãos em areias e arenitos. Arquivos de Biologia e Tecnologia, v.10, p.253-275, 1955.

BIGARELLA, J.J. Estrutura e origem das paisagens tropicais. v.1, Florianópolis: Ed. UFSC, 1994.

BLOTT, S.J.; PYE, K. Particle shape: a review and new methos of characterization and classification. Sedimentology, v.55, p.31-63, 2008.

CAILlEAUX, A.; TRICART, J. Initiation à l'étude des sables et galets. CDU, 5 pi. De la Sorbonne, Paris, v.1, 369p., 1963.

CASSETI, V. Geomorfologia. [S.1.]: [2005]. Disponível em: <www.funape.org.br/geomorfologia/>. Acesso em: 21 set. 2015.

COX, E.A. A method for assigning numerical and percentage values to the degree of roundness of sand grains. Journal of Paleontology. v.1, n.3, p.179-183, 1927.

DIAS, J.A. A Análise Sedimentar e o Conhecimento dos Sistemas Marinhos, 2014. E-book disponível online em: <http://www.oceanografia.ufba.br/ftp/Sedimentologia/Bibliografia/Alverino_Dias_Analise\%20Sedimentar\% 20Sistemas\%20Marinhos_2004.pdf >. Acesso em: 08 Jan. 2017.

EMPRESA BRASILEIRA DE PESQUISA AGROPECUÁRIA - EMBRAPA. Sistema Brasileiro de Classificação de solos. 3 ed. ver. Ampl. Brasília, DF: Embrapa, 353p. 2013. 
GRAHAN, J. Collection and analysis of field data. In: TUCKER, M. Techniques in Sedimentology. Oxford: Editora Blackwell Scientific Publications, 1988, Cap. 2, p.5-62.

HIRUMA, S.T. Revisão dos conhecimentos sobre o significado das linhas de seixos. Revista do Instituto Geológico, São Paulo, v.27-28, n.1/2, p. 53-64, 2007.

HOFMANN, M. GIS-based Analysis of Geo-Potentials for a Tropical Metropolitan Area: the Northern Periphery of Belo Horizonte (Minas Gerais, Brazil). PhD Thesis, TU Darmstadt, 333p, 2014. URL: http://tuprints.ulb.tu-darmstadt.de/4152 URN: urn:nbn:de:tuda-tuprints-41522, 2014.

KOHLER, H.C. Estudo do relevo cárstico de Lagoa Santa. 1989. 113f. (Doutorado em Geografia Física). Universidade de São Paulo, São Paulo, 1989.

PENTEADO, M.M. Fundamentos de Geomorfologia. $3^{\text {a }}$ Ed. Fundação Instituto Brasileiro de Geografia e Estatística : Rio de Janeiro, 186p. 1983.

PENTLAND, A. A method of measuring the angularity of sands. Royal Society of Canada. (ser. 3), .21, 1927.

PILÓ, L.B. Morfologia cárstica e materiais constituintes: dinâmica e evolução da depressão poligonal Macacos-Baú - carste de Lagoa Santa, MG. 1998. 283f. (Doutorado em Geografia Física) - Universidade de São Paulo, São Paulo, 1998.

PINTO, R.C. Eventos deposicionais cenozóicos no médio vale do rio das Velhas: paleoníveis deposicionais e dinâmica fluvial. 2009. 216f. (Doutorado em Geografia e Análise Ambiental) - Instituto de Geociências da Universidade Federal de Minas Gerais, Belo Horizonte, 2009.

QUEIROZ-NETO, J.P. O estudo das formações superficiais no Brasil. Revista do Instituto Geológico, São Paulo, v.22 n. 112, p.65-78, 2001.

RIBEIRO, S.; BONETTI, C. Variabilidade morfométrica de sedimentos arenosos: revisão de métodos e uso do software ImageJ na diferenciação de ambientes deposicionais na Ilha de Santa Catarina e região continental, SC, Brasil. Gravel, v.11, n.1, p.37-47, 2013.

SANTOS, L.J.C.; SALGADO, A.A.R.; RAKSSA, M.L.; MARENT, B.R. Gênese das linhas de Pedra. Revista Brasileira de Geomorfologia, v.11, n.2, p.103-108, 2010.

SCHAEFER, C.E.R. Brazilian latosols and their B horizon microstructure as long-term biotic constructs. Australian Journal of Soil Research, CSIRO Publishing, Collingwood, Australia, v.39, p.909-926, 2001.

SEGALEN, P. Le remaniement des sols et la mise en place de la stone-line en Afrique. Cah. Orstom, ser. Pedologie, v.7, n.1, p. 113-131, 1969.

SILVA, A.B. Hidrogeologia de Meios Cársticos. Cap. 3.2, 1995. Disponível em: <www.nehma.ufba.br/cursos/apostilas_monografia/Graduacao/LIVROtexto.pdf> Acesso em: 5 jan. 2017.

SUGUIO, K., Introdução a sedimentologia. São Paulo. Ed. Edgard Blucher. EDUSP, 317 p. 1973.

THOMAS, M.F. Geomorphology in the tropics : a study of weathering and denudation in low latitudes. John Wiley and Sons Ltd: Chichester, England, 460p. 1994. 